\title{
Probabilistic Life Models for Steel Structures Subject to Creep- Fatigue Damage
}

\author{
Fatmagul Ibisoglu, Mohammad Modarres \\ University of Maryland, Center for Risk and Reliability, College Park, MD, 20740, USA \\ fibisogl@umd.edu \\ modarres@umd.edu
}

\begin{abstract}
When metal structures are subjected to long-term cyclic loading at high temperature, simultaneous creep and fatigue damage may occur. In this paper probabilistic life models, described by hold times in tension and total strain range at elevated temperature have been derived based on the creeprupture behavior of $316 \mathrm{FR}$ austenitic stainless steel, which is one of the candidate structural materials for fast reactors and future Generation IV nuclear power plants operating at high temperatures. The parameters of the proposed creepfatigue model were estimated using a standard Bayesian regression approach. This approach has been performed using the WinBUGS software tool, which is an open source Bayesian analysis software tool that uses the Markov Chain Monte Carlo sampling method. The results have shown a reasonable fit between the experimental data and the proposed probabilistic creep-fatigue life assessment models. The models are useful for predicting expended life of the critical structures in advanced high temperature reactors when performing structural health management.
\end{abstract}

\section{INTRODUCTION}

Interest in future reactor designs focuses on Generation IV nuclear power plants. In the design of fast reactor structural materials, the most important failure mode to be prevented is creep-fatigue (CF) damage at elevated temperatures. The development of a procedure for evaluating $\mathrm{CF}$ life is essential for safety and reliability of reactor structures. Other important damage mechanisms such as the irradiation damage to structural materials such as the reactor vessel of a fast reactor is not as severe as that of core materials such as a cladding tube. However, the structural materials are continuously exposed to irradiation and CF for a long period of time, and they are extremely hard to replace. This makes

Fatmagul Ibisoglu \& Mohammad Modarres. This is an open-access article distributed under the terms of the Creative Commons Attribution 3.0 United States License, which permits unrestricted use, distribution, and reproduction in any medium, provided the original author and source are credited. the use of degradation models to monitor and assess the prognosis of the structural materials very important.

The austenitic stainless steel 316 is of current interest as one of the candidate structural materials for these fast reactors as they are expected to operate at very high temperatures. In this paper, the $316 \mathrm{FR}$ stainless steel has been subjected to low loading rates, cyclic frequencies and temperatures at $550-600^{\circ} \mathrm{C}$ to develop probabilistic models for $\mathrm{CF}$ degradation and expended life assessment of reactor structures. Effect of irradiation on some of the structural materials subject to high irradiation damage such as fuel cladding and control rods is important, but outside of the scope of this paper.

Fatigue and creep are two important failure mechanisms with strong synergy leading to damage in components and structures under cyclic loading at elevated temperatures. A number of standard methods and guidelines exist for design and life assessment of structures subject to cyclic high temperature (Riou, 2008; Asayama \& Tachibana, 2007; Asayama, 2009). Most of these are methods where creep and fatigue life fractions of the loading history are evaluated separately, combined as additive quantities, and compared to case- or material-specific limits. These methods fail to explicitly account for the synergy that exists between these two failure mechanisms.

In many engineering applications the loading rates and cyclic frequencies are low, so that the combined CF damage is creep dominated. When the loading rates and cyclic frequencies are high, the combined $\mathrm{CF}$ damage is fatigue dominated. In most cases, however, both mechanisms contribute and it is the combined synergy that dominates. To improve the fitness of data to CF models, this paper introduces a new methodology for CF life assessment that does not separate creep and fatigue damage models, whereby the synergy between the two mechanisms can be explicitly included. Probabilistic degradation and damage models, described by the hold times in tension and total 
strain range at temperature, have been derived based on the creep rupture behavior of 316 stainless steel (316FR) (Takahashi et al., 2008a; see the Appendix). The prior estimates of the model parameters are updated using the Bayesian regression approach applied to $29 \mathrm{CF}$ data points with hold times ranging from $6 \mathrm{~min}$ to $10 \mathrm{~h}$ at 550 and $600^{\circ}$ C (Takahashi et al., 2008b). Data from isothermal CF tests under strain control, with stress ratio of $\mathrm{R}=-1$ and hold periods in tension were included.

This paper first describes an overview of the important relevant literature, followed by a review of the life models of structures subject to $\mathrm{CF}$. An overview of the $\mathrm{CF}$ experimental results using 316FR data will then be discussed. The proposed probabilistic CF damage assessment models will be estimated and compared based on 316FR CF data set (Takahashi et al., 2008b). Finally, conclusions will be presented.

\section{BACKGROUND}

\subsection{Factors Affecting CF Life}

Brinkman (1985) identified influence of important factors on the time-dependent fatigue life. A comprehensive discussion of the factors affecting CF life is presented in Ibisoglu (2013). This paper briefly explains these key factors as following:

1. Metallurgical state: Factors of microstructural composition, carbon content and heat treatment on ductility play significant role in defining metallurgical states. These elements are:

- Microstructural composition: Brinkman (1985) observed that small grain sizes and presence of fine and closely packed intergranular precipitates improved the life of metals. Intergranular precipitate was restricting grain-boundary sliding and limiting the wedge cracking. Furthermore, as the grain size decreased, time-dependent fatigue behavior improves, except for the low-cycle fatigue regime.

- Carbon content: Takahashi et al. (2008a) examined the type 304 stainless steel used in a prototype fast reactor vessel in Japan. This material was later replaced with low-carbon and nitrogencontrolled 316FR stainless steel weld material. Takahashi et al. (2008a) reported the reduced carbon content of $316 \mathrm{FR}$ as the reason for considerably better creep strength, obtained by reducing the chromium carbide $(\mathrm{CrC})$ precipitation along grain boundaries, which promotes initiation of creep cavities.

- Heat treatments on ductility: Solution heat treatment (e.g. $1250^{\circ} \mathrm{C}, 16 \mathrm{~h}$ ) prior to rolling reduces the possibility of carbide precipitation by homogenizing chromium distribution. Under this condition, the material shows a longer life. This trend coincides with the fact that ductility in creep tests has a strong correlation between creep ductility and CF life (Takahashi et al., 2008b).

2. Wave form and frequency: Tensile hold periods appear to be more damaging at high temperatures (e.g., $650^{\circ} \mathrm{C}$ ) than the corresponding compressive hold periods at high strain ranges (e.g., 1\%), but the reverse is true at lower strain ranges (e.g., $0.4 \%$ ). At higher temperatures (e.g., $760^{\circ} \mathrm{C}$ ) tensile hold periods appear to consistently be the most damaging. Increasing duration of the hold period reduces the fatigue life (Takahashi et al., 2008b). Two specific mechanisms can lead to intergranular crack formation and fracture in ploycrystalline including formation of intergranular creep cavities and by grain boundary triple-point nucleation voidage as a result of localized grain boundary sliding. The latter mechanism usually occurs at higher stresses (approaching the yield strength), which occurs in low- to intermediate-cycle fatigue applications. Under tensile loads held at elevated temperatures, high enough for creep to occur, intergranular voids form easily, which in turn favors intergranular fatigue crack propagation. Increasing the temperature within the creep range or decreasing the cyclic frequency further weakens the grain boundaries with respect to the intergranular matrix material and promotes grain boundary sliding, resulting in decreased cyclic life for a given specimen geometry (Brinkman, 1985).

3. Environmental factors: It is known that constant loading at high temperature reduces the number of cycles-to-failure as compared to pure fatigue loading due to additional creep damage or other mechanisms such as oxidation. Failure life at $600^{\circ} \mathrm{C}$ tends to be shorter than that at $550^{\circ} \mathrm{C}$, but the difference is much smaller than observed in pure-creep tests (Takahashi et al., 2008b).

4. Complex loading path histories: For the type 304 stainless steel, previous studies have performed straincontrolled hold time tests with the strain held at the peak strain amplitudes (Takahashi et al., 2008b). It has been concluded that: (1) Tensile hold times at peak strain value are more damaging than compressive hold times of equal duration; (2) Hold periods imposed at other locations on the hysteresis loops, such as zero stress or zero relaxation points, degrade fatigue life but not as much as hold periods imposed at peak tensile strain values; (3) Hold periods imposed on the tensiongoing side of the loop tend to be more detrimental than those imposed on the compression-going side; (4) The rate of accumulation of a given amount of relaxation or creep strain is important in that lower creep rates favor intergranular cavitation and hence result in lower fatigue life (Brinkman, 1985). 
5. Classical creep damage (voidage): Creep is modeled as time-dependent deformation, and thereby is mathematically distinct from elastic and plastic deformation. Elastic and plastic deformations are mathematically modeled as instantaneous deformations occurring in response to applied stresses. In reality, all deformations are time dependent, but the characteristic times for elastic and plastic deformations are orders of magnitude smaller than those for creep. At elevated temperatures, most materials can fail at a stress that is much lower than its ultimate strength measured at ambient temperature. These failures are timedependent and are caused by creep rupture (Fatemi \& Yang, 1998).

\subsection{Overview of CF Life Assessment Models}

In this section we summarize the more recent high temperature $\mathrm{CF}$ life methods. A comprehensive review for CF life methods is presented in Ibisoglu (2013). Jeong et al. (2001) proposed a normalized life prediction model in terms of stress relaxation during the hold time under $\mathrm{CF}$ conditions. Assuming the principle that the reduction of fatigue life with hold time is due to the creep effect of stress relaxation, the relaxed stress range was considered as a $\mathrm{CF}$ damage function. The CF data from Jeong et al. is used to check the validity of the proposed life prediction model in this paper. It was shown that the data satisfied the applicability of the proposed normalized life relation model. Accordingly, using this life prediction model, one may realize that all the Coffin-Manson plots at the various levels of hold time under strain-controlled CF tests can be normalized to make one master curve.

Nam (2002) showed that grain boundaries are one of the detrimental processes for the degradation of austenitic stainless steels. Grain boundary cavitation reduces the CF life at high temperatures. Nam proposed a damage function based on a model for the CF life prediction in terms of nucleation and growth of grain boundary cavities for austenitic stainless steel. Using this damage function, it may be shown that the Coffin-Manson plots at the various levels of tensile hold time and temperature under strain controlled CF tests can be normalized to one master curve. This would allow calculation of the expected CF life for austenitic stainless steels under tensile hold hightemperature low-cycle fatigue test conditions.

JianPing et al. (2003) proposed a nonlinear CDM model to assess the CF life of a steam turbine rotor, where the effects of complex multi-axial stress and the coupling of fatigue and creep are taken into account. The model was applied to a $600 \mathrm{MW}$ steam turbine under a practical start-stop operation. The results were compared with those from the linear damage accumulation theory that is the predominant method in life assessment of steam turbine rotors. The comparison showed that the nonlinear CDM model describes the accumulation of damage better than the linear accumulation theory (see JianPing et al. (2003), Figure 8, p.394).

Goswami (2004) presented a databank that was compiled from published and unpublished sources. Phenomenological methods of CF life prediction were summarized in a table showing the number of material parameters required by each method and type of tests needed to generate such parameters. Applicability of viscosity method was assessed with $\mathrm{CF}$ data from $1 \mathrm{Cr}-\mathrm{Mo}-\mathrm{V}, 2.25 \mathrm{Cr}-\mathrm{Mo}$ and $9 \mathrm{Cr}-1 \mathrm{Mo}$ steels. Goswami developed generic equations to predict CF life of high temperature materials. Statistical analyses estimated the coefficient of correlation and normal distribution plots in order to make recommendations for the design of components operating at high temperatures.

Scholz and Berger (2005) developed a phenomenological lifetime prediction concept for multi-staged CF loading. The concept demonstrates the applicability of rules for synthesis of stress-strain path and relaxation including an internal stress concept as well as mean stress effects. Further, Scholz and Berger developed a CF interaction concept. Service-type experiments conducted at different strain rates and hold times for verification purposes demonstrated the acceptability of this life prediction method for variation of conventional $1 \% \mathrm{Cr}$-steels as well as modern high chromium 9-10\%Cr-steels (see Scholz \& Berger, 2005, Figure 19, p.729).

Shang et al. (2007) proposed a multi-axial fatigue damage parameter based on the critical plane approach to calculate the pure fatigue damage under uniaxial/multi-axial loading at constant high temperatures. For fully reversed low-cycle fatigue loading under low frequency at high temperature, one-half of the maximum equivalent stress response value at cyclic stabilization was used as the creep stress to evaluate the multi-axial creep damage. The linear damage accumulation rule was used to predict the multi-axial CF life at high temperature. The $\mathrm{CF}$ experimental data of thin tubular specimens made from GH4169 superalloy and $2.25 \mathrm{Cr}-1 \mathrm{Mo}$ steel were used to verify the proposed CF life prediction model. The results showed that the proposed CF damage calculation model could be used under either uniaxial or multi-axial non-proportional loading at high temperature. The proposed model was used to predict multi-axial CF life, and a good agreement was demonstrated with the experimental data (see Shang et al. (2007), Figure 5 \& 6, pp.710,712).

Fan et al. (2007) performed high-temperature stress controlled tests for $1.25 \mathrm{Cr} 0.5 \mathrm{Mo}$ steel at different loading conditions to investigate $\mathrm{CF}$ interaction behavior and established character maps. They found that when the stress amplitude was less than the mean stress, short/drastic interactions between fatigue and creep will occur and the fracture life will decrease rapidly and fracture ductility will reach its minimum. The complex relationships between fracture life and its influencing factors can be well explained by the mean strain rate at half-life, which is considered as 
the main factor associated with the fracture life (Fan et al., 2007). Fan et al. also proposed a new model for CF life prediction under stress control based on the ductility exhaustion theory and the effective stress concept.

Takahashi et al. (2008b) developed a low-carbon, nitrogencontrolled 316 stainless steel (i.e., 316FR), and regarded it as the principal candidate for a main structural material of the liquid metal-cooled fast breeder reactor plants in Japan. They conducted a number of uniaxial CF to develop a CF evaluation method. Long-term data up to $35,000 \mathrm{~h}$ was obtained and applicability of failure life prediction methods was studied based upon the results. Takahashi et al. also tested cruciform shaped specimens under biaxial loading conditions to examine the effect of multi-axial stress on failure life under CF condition.

Chen et al. (2008) performed high-temperature low-cycle fatigue tests with and without a 10 s strain hold period within each cycle. These tests were performed on the nickel base superalloy GH4049 under a fully reversed axial total strain control mode. Three CF life prediction methods were chosen to analyze the experimental data. These methods were the linear damage summation (LDS) (Lloyd \& Wareing, 1981) the strain range partitioning (SRP (Lloyd \& Wareing, 1981; National Aeronautics and Space Administration [NASA], 1971)) and strain energy partitioning (SEP (He et al., 1985)). Their ability to predict the $\mathrm{CF}$ lives of $\mathrm{GH} 4049$ at $700^{\circ} \mathrm{C}, 800^{\circ} \mathrm{C}$ and $850^{\circ} \mathrm{C}$ was evaluated. It was found that SEP method showed an advantage over the SRP method for all the tests under consideration. At $850^{\circ} \mathrm{C}$, the LDS and SEP methods offered a more satisfactory prediction for $\mathrm{CF}$ lives. At the temperatures of $700^{\circ} \mathrm{C}$ and $800^{\circ} \mathrm{C}$, the SRP and SEP method was able to correlate the life data better than the LDS method. In addition the differences in predictive ability of these methods were also analyzed.

Zhang et al. (2012) discussed time-dependent creep and cycle-dependent fatigue of nickel-based super alloys. Three different kinds of CF life models were investigated for the nickel-based super alloys. Effects of temperature, loading ratio and loading hold time on material failure were considered. Comparison with experiments revealed that the linear accumulation concept based on the Forman model (Forman, 1972) provided reasonable results of the CF interaction if the life is dominated by mechanical fatigue damage. For higher loading ratios, however, deviations became significant. In the lower frequency region, the modified FCE models (Nicholas, 1990; Parida \& Nicholas, 1992) and Saxena models (Saxena, 1980) gave more reasonable predictions, but showed large discrepancy to tests with hold time. The modified Saxena model contained as separate term for hold time effects and agreed with the experimental observations more accurately (see Zhang et al. (2012), Figure 5, p.85).

Holmström and Auerkari (2013) proposed a new robust model for CF life assessment. The model was proposed with a minimal set of model parameters, and without the need to separate creep and fatigue damage or life fractions. The model was based on creep-rupture behavior of the material with a fatigue correction described on hold time (in tension) and total strain range at temperature. The model was shown to predict the observed CF life of ferritic steel P91, austenitic steel 316FR, and Ni alloy A230 with a scatter band close to the factor of 2 (Holmström \& Auerkari, 2013). Holmström et al. (2013) established new creep models for predicting creep strain and rupture of $316 \mathrm{~L}$ and $316 \mathrm{~L}(\mathrm{~N})$ using the Wilshire equations and the logistic creep strain model. The established models were extended to creep-fatigue and applied to characterize the steels 316FR and $316 \mathrm{~L}$ in terms of the linear fraction rule.

\begin{tabular}{l|l}
\hline $\begin{array}{l}\text { Name of the life } \\
\text { prediction model }\end{array}$ & Life prediction model \\
\hline $\begin{array}{l}\text { Cumulative linear } \\
\text { damage (Lloyd \& } \\
\text { Wareing, 1981) }\end{array}$ & $1=\sum \mathrm{N} / \mathrm{N}_{\mathrm{f}}+\sum \mathrm{t} / \mathrm{t}_{\mathrm{r}}$ \\
\hline $\begin{array}{l}\text { Robust Fii (Holmström } \\
\& \text { Auerkari, 2013) }\end{array}$ & $\Phi_{\mathrm{m}}=\exp \left\{-\mathrm{k}\left[\mathrm{t}_{\mathrm{CF}} \exp \left(-\frac{\mathrm{Q}_{\mathrm{c}}^{*}}{\mathrm{RT}}\right)\right]^{\mathrm{u}}\right\}$ \\
& $\left.\mathrm{N}_{\mathrm{CF}}=\frac{\mathrm{t}_{\mathrm{CF}}\left(\Phi_{\mathrm{CF}}\right)}{\mathrm{t}_{\mathrm{h}}}+\mathrm{t}_{\mathrm{h}}, \mathrm{T}\right)=\mathrm{c}_{1}+\frac{\mathrm{c}_{2}}{\Delta \varepsilon}+\mathrm{c}_{3} \log \left(\mathrm{t}_{\mathrm{h}}\right)$ \\
\hline
\end{tabular}

Table 1. Summary of the precursor CF life prediction methods in this study

Table 1 summarizes the mathematical forms of the CF life prediction models adopted in this paper. The adopted models (Holmström \& Auerkari, 2013) in this paper are applicable for many CF cases in power generation where strain rates and cyclic frequencies are low and even lower (more creep dominated). The $\Phi$ function in Holmström and Auerkari (2013) can be made to predict LCF properties by determining effective hold times for the specified stress ratio and cyclic frequency. This feature enables calculation of $\mathrm{N}_{\mathrm{CF}} / \mathrm{N}_{\mathrm{fo}}$, representing the approach in design standards (Cumulative linear damage rule (Lloyd et al., 1981)). In this paper, a CF damage approach was applied to some leading creep rupture models to see if there is a model - in addition to Wilshire equation in Holmström and Auerkari (2013) that would more effectively predicts the CF life of the 316 FR stainless steel.

The most commonly used creep rupture models are the Larson-Miller (1952) and the Mason-Haferd (1953) models. One main problem with these models is that the polynomial characteristics of the models can lead to turn-back and sigmoidal behavior when predicting outside of the data range. Two Soviet Models (Trunin et al., 1971) are better than the polynomial time-temperature parameters and do not easily produce turn-back and sigmoidal behavior. In this paper, the best known Larson-Miller, Mason-Haferd, OrrSherby Dorn (1954), Soviet Models (SM1 \& SM2) and Wilshire (Wilshire et al., 2009) models were modified and 
used to predict CF life of 316 FR material, provided the methodology in Holmström and Auerkari (2013).

\begin{tabular}{l|l}
\hline Creep Model & Corresponding Modified CF Life Prediction Model \\
\hline Larson-Miller (1952) & $\log \left(\mathrm{t}_{\mathrm{CF}}\right)=\left\{\sum_{\mathrm{k}=0}^{\mathrm{n}} \beta_{\mathrm{k}}\left(\log \left[\sigma_{\mathrm{ref}}\right]\right)^{\mathrm{k}}\right\} / \mathrm{T}+\beta_{3}$ \\
\hline Manson-Haferd (1953) & $\log \left(\mathrm{t}_{\mathrm{CF}}\right)=\left\{\sum_{\mathrm{k}=0}^{\mathrm{n}} \beta_{\mathrm{k}}\left(\log \left[\sigma_{\mathrm{ref}}\right]^{\mathrm{k}}\right)\right\}\left(\mathrm{T}-\mathrm{T}_{0}\right)+\beta_{3}$ \\
\hline Orr-Sherby Dorn (1954) & $\log \left(\mathrm{t}_{\mathrm{CF}}\right)=\left\{\sum_{\mathrm{k}=0}^{\mathrm{n}} \beta_{\mathrm{k}}\left(\log \left[\sigma_{\mathrm{ref}}\right]^{\mathrm{k}}\right)\right\}+\beta_{3} / \mathrm{T}$ \\
\hline Soviet Model 1 \& 2(Trunin et al. 1971) & $\log \left(\mathrm{t}_{\mathrm{CF}}\right)=\beta_{0}+\beta_{1} \cdot \log [\mathrm{T}]+\beta_{2} \cdot \log \left[\sigma_{\mathrm{ref}}\right]+\frac{\beta_{3}}{\mathrm{~T}}+\beta_{4} \cdot \frac{\sigma_{\mathrm{ref}}}{\mathrm{T}}$ \\
\hline Wilshire (2009) & $\log \left(\mathrm{t}_{\mathrm{CF}}\right)=\left(\frac{\ln \left(\frac{\sigma_{\mathrm{ref}}}{\sigma_{\mathrm{UTS}}}\right)}{-\mathrm{k}}\right)^{\frac{1}{\mathrm{u}}} \cdot \frac{1}{\exp \left(\frac{-Q}{8.314 \cdot \mathrm{T}}\right)}$ \\
\hline
\end{tabular}

Table 2. Leading creep-rupture models modification for CF applications in this study

\section{MOdel DeVElopment for CF Life}

In this study modifications were made to the rupture time and stress variables of the leading models mentioned in the previous section. A creep-rupture model can be used to assess CF life in materials under elevated temperature only if $t_{r}=t_{C F}=\sum t_{h}$ is used instead of the creep-rupture time variable (Holmström \& Auerkari, 2013). In the modified models $\sigma_{0}$ is assumed to be the reference stress $\left(\sigma_{\text {ref }}\right)$ in each strain controlled tensile hold $\mathrm{CF}$ test data. The following models were modified: The Larson-Miller, Manson-Haferd, Orr-Sherby Dorn and two generalized SM1 \& SM2 (see Anon. Code Case N-47 (1976) for more discussions).

The general creep-rupture parameter introduced in NASA (1963) has the following form:

$$
\mathrm{P}(\sigma)=\frac{\frac{\log \mathrm{t}}{\sigma^{\mathrm{q}}}-\log \mathrm{t}_{0}}{\left(\mathrm{~T}-\mathrm{T}_{0}\right)^{\mathrm{r}}}
$$

where $T_{0}, \log t_{0}, \mathrm{q}$ and $\mathrm{r}$ are material constants to be determined from the experimental data. The parameter of $P(\sigma)$ is a function of the stress. If $q=0$ and $r=1$, the Mason-Haferd parameter is obtained. If $\mathrm{q}=0, \mathrm{r}=-1$ and $\mathrm{T}_{0}=-460^{\circ} \mathrm{F}$, the Larson-Miller parameter results (NASA, 1965). If $q=0$ and $r=0$, Orr-Sherby Dorn parameter results.

Soviet prediction method can be described by the following model (SM1 \& SM2) (Trunin et al., 1971):

$\log \left(\mathrm{t}_{\mathrm{r}}\right)=\beta_{0}+\beta_{1} \cdot \log [\mathrm{T}]+\beta_{2} \cdot \log \left[\sigma_{0}\right]+\frac{\beta_{3}}{\mathrm{~T}}+\beta_{4} \cdot \frac{\sigma_{0}}{\mathrm{~T}}$

Soviet is highly effective in modeling the known rupture times, but is totally inadequate for predicting beyond the range of input data. However, this limitation to generalize and the model's tendency to over-fit the interpolative data set, is a characteristic of all parameters (Evans, 1999).
The Wilshire model (Wilshire et al., 2009) for time to rupture $t_{r}$ at stress $\sigma(\mathrm{MPa})$ and temperature $\mathrm{T}(\mathrm{K})$ is expressed as:

$$
\log \left(\mathrm{t}_{\mathrm{r}}\right)=\left(\frac{\ln \left(\frac{\sigma_{0}}{\sigma_{\mathrm{UTS}}}\right)}{-\mathrm{k}}\right)^{\frac{1}{\mathrm{u}}} \cdot \frac{1}{\exp \left(\frac{-\mathrm{Q}}{8.314 \mathrm{~T}}\right)}
$$

where $\mathrm{k}$ and $\mathrm{u}$ are constants obtained by fitting to the test data, $\mathrm{Q}$ is the apparent activation energy and $\sigma_{\mathrm{UTS}}$ is the tensile strength at the specified temperature. Application of this model requires data from both creep-rupture testing and tensile testing.

The modified models proposed in this study have been summarized in Table 2. A significant advantage of these modified models is that they can predict CF life for a given isothermal test type without needing the detailed information of the individual $\mathrm{CF}$ cycles, including relaxation, peak stress, softening or hardening behavior.

\section{Estimation of Model Parameters Using BAYESIAN REGRESSION}

In the Bayesian regression approach, parameters of interest in the modified models and the Wilshire model are treated as uncertain. A joint PDF represents prior information of the model parameters and a posterior joint PDF is derived by simulation through the Bayesian inference formalism. The Bayesian framework for estimating the vector of parameters, $\boldsymbol{\theta}$, of a model is depicted by the flowchart in Figure 1 (Modarres et al., 2010).

Tools such as WinBUGS using the Gibbs sampling (which is a specific form of Markov Chain Monte Carlo sampling) allow one to draw samples from the established posterior distribution (using observed data, and choosing suitable prior) (Wendell, 2011). 


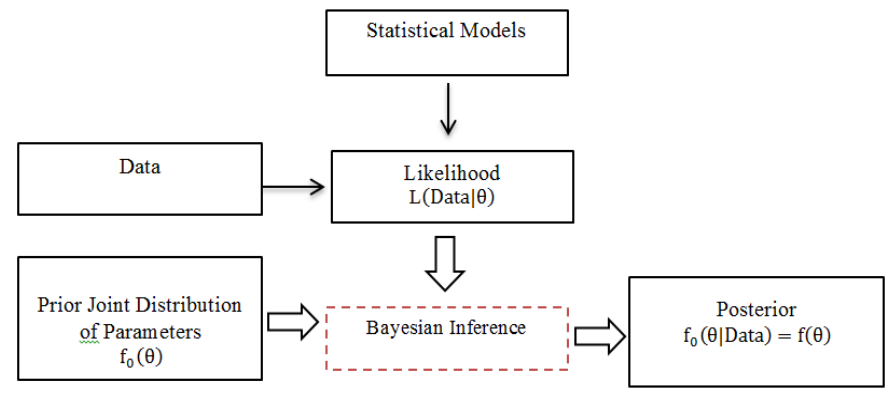

Figure 1. The Bayesian regression framework

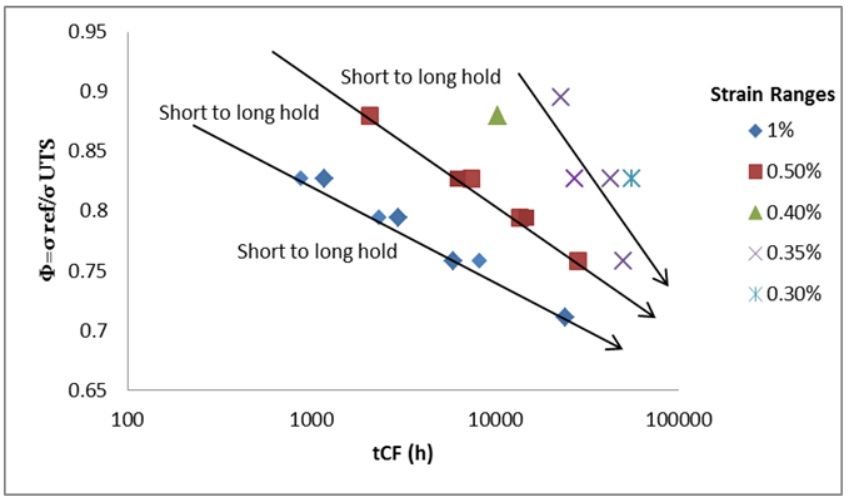

(a)

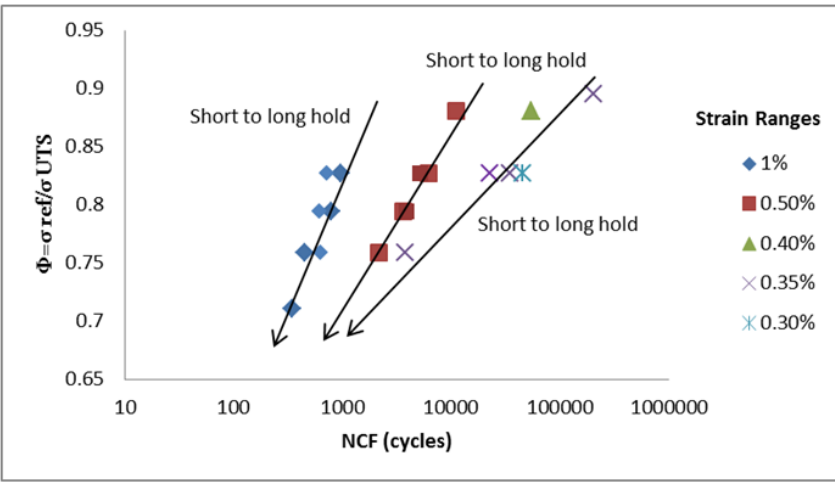

(b)

Figure 2. (a) Normalised reference stress $\boldsymbol{\Phi}$ as a function of $\boldsymbol{t}_{\boldsymbol{C} F}$, (b) normalised reference stress $\Phi$ as a function of $\boldsymbol{N}_{\boldsymbol{C} F}$

\subsection{Bayesian Estimation of the CF Adjusted Larson Miller Model Parameters}

The modified CF Larson-Miller model (Larson \& Miller, 1952) is presented in Table 2. Assuming a normal distribution to represent the CF logarithmic expended life, the log-likelihood function of the $\mathrm{CF}$ data and the corresponding different percentiles of this distribution can be expressed as:

$$
\mathrm{f}\left(\log \left(\mathrm{t}_{\mathrm{CF}}\right)\right)=\mathrm{N}(\mu, \mathrm{s})
$$

where, $\mu$ and $s$ are the normal-mean and normal-standard deviation of the $\mathrm{CF}$ life distribution. The corresponding log-likelihood function assuming the PDF in Eq. (4) would be:

$$
\begin{aligned}
& \mathrm{L}\left(\log \left(\mathrm{t}_{C F}\right) \mid \beta_{0}, \beta_{1}, \beta_{2}, \beta_{3}, s\right) \\
& =\prod_{\mathrm{i}=1}^{\mathrm{N}} \mathrm{f}\left(\log \left(\mathrm{t}_{\mathrm{CF}_{i}}\right) \mid \sigma_{\text {max }_{\mathrm{i}}}, \mathrm{T}_{\mathrm{i}}, \beta_{0}, \beta_{1}, \beta_{2}, \beta_{3}, s\right)
\end{aligned}
$$

The data points obtained from $\mathrm{CF}$ experiments involving 304FR sample used as data in Eq. (5) are presented in Figure 2 (a) and (b) and discussed in detail in Ibisoglu (2013). Takahashi et al. (2008b) conducted a number of tensile strain-hold, trapezoidal-wave, $\mathrm{CF}$ tests at $550^{\circ} \mathrm{C}$. Strain rate during ramping period was fixed at $0.1 \% / \mathrm{s}$. Life was defined as the cycle when the tensile peak stress became smaller than $75 \%$ of its maximum value experienced during the test. The largest and smallest strain ranges were $1.0 \%$ and $0.3 \%$, respectively, whereas the hold time was varied between $0.1 \mathrm{~h}$ and $50 \mathrm{~h}$ (Takahashi, 2008b). The data used as prior PDF in the Bayesian regression are available in Ibisoglu (2013). The posterior joint PDF of the model parameters, $\beta_{0}, \beta_{1}, \beta_{2}, \beta_{3}$, and the standard deviation, $\mathrm{s}$, can be obtained from:

$$
\begin{gathered}
\mathrm{f}\left(\beta_{0}, \beta_{1}, \beta_{2}, \beta_{3}, s \mid \log \left(\mathrm{t}_{\mathrm{CF}}\right)\right)= \\
\frac{\mathrm{f}_{0}\left(\beta_{0}, \beta_{1}, \beta_{2}, \beta_{3}, s\right) \cdot \mathrm{L}\left(\log \left(\mathrm{t}_{C F}\right) \mid \beta_{0}, \beta_{1}, \beta_{2}, \beta_{3}, s\right)}{\int_{s} \int_{\beta_{2}} \int_{\beta_{1}} \int_{\beta_{0}} \mathrm{f}_{0}\left(\beta_{0}, \beta_{1}, \beta_{2}, \beta_{3}, s\right) \cdot \mathrm{L}\left(\log \left(\mathrm{t}_{\mathrm{CF}}\right) \mid \beta_{0}, \beta_{1}, \beta_{2} \beta_{3}, s\right) \mathrm{d} \beta_{0} \mathrm{~d} \beta_{1} \mathrm{~d} \beta_{2} \mathrm{~d} \beta_{3} \mathrm{ds}}
\end{gathered}
$$

where $\mathrm{f}_{0}\left(\beta_{0}, \beta_{1}, \beta_{2}, \mathrm{~s}\right)$ is the prior joint PDF for parameters $\beta_{0}, \beta_{1}, \beta_{2}, \beta_{3}$,s (Pavese et al., 2012). WinBUGS software tool was used to solve Eq. (6). The statistics of the marginal posterior PDF of the parameters of the modified CF LarsonMiller model using Eq. (6) are presented in Table 3.

\begin{tabular}{c|l}
\hline Parameter & Mean \\
\hline$\beta_{0}$ & 404.0000 \\
\hline$\beta_{1}$ & -53.4700 \\
\hline$\beta_{2}$ & -603.8000 \\
\hline$\beta_{3}$ & 27.6900 \\
\hline$s$ & 0.4892
\end{tabular}

Table 3. WinBUGS statistics for the modified CF Bayesian Larson-Miller model parameters

\subsection{Bayesian Estimation of the Modified CF Manson Haferd Model}

The modified CF Manson-Haferd Model (NASA, 1953) is presented in Table 2. This form of the model was used in the subsequent Bayesian inference framework steps. The parameter $\mathrm{T}_{0}$ in this model is recommended to be 450 to correlate the CF data (Zhao et al., 2010). The likelihood function is given by Eq. (5) and the posterior joint PDF of parameters $\beta_{0}, \beta_{1}, \beta_{2}, \beta_{3}$ and s by Eq. (6). The data points used to evaluate Eq. (5) are presented in Fig. 2 (a) and (b) (Ibisoglu, 2013). Table 4 summarizes the results of the estimated parameters. 


\begin{tabular}{c|l}
\hline Parameter & Mean \\
\hline$\beta_{0}$ & 0.2528 \\
\hline$\beta_{1}$ & -0.1433 \\
\hline$\beta_{2}$ & 0.0183 \\
\hline$\beta_{3}$ & 0.1382 \\
\hline$s$ & 0.1680 \\
\hline
\end{tabular}

Table 4. WinBUGS statistics of the modified CF MansonHaferd model parameters

\subsection{Bayesian Estimation of the Modified CF Orr-Sherby Dorn Model}

The modified CF Orr-Sherby Dorn Model (Orr et al., 1954) is presented in Table 2. The corresponding likelihood function is given by Eq. (5) and the posterior joint PDF of parameters $\beta_{0}, \beta_{1}, \beta_{2}, \beta_{3}$ and s by Eq. (6). The data points used to evaluate Eq. (5) are presented in Figure 2 (a) and (b) (Ibisoglu, 2013). Table 5 summarizes the results of the estimated parameters.

\begin{tabular}{c|l}
\hline Parameter & Mean \\
\hline$\beta_{0}$ & 3.8160 \\
\hline$\beta_{1}$ & 8.4350 \\
\hline$\beta_{2}$ & -1.4890 \\
\hline$\beta_{3}$ & 0.9941 \\
\hline $\mathrm{s}$ & 4.1650 \\
\hline
\end{tabular}

Table 5. WinBUGS statistics of the modified CF OrrSherby Dorn model parameters

\subsection{Bayesian Estimation of the CF Adjusted Soviet Model}

The modified CF Soviet Model (Trunin et al., 1971) is presented in Table 2. The likelihood function is given by the same form as the one in Eq. (5) and the posterior joint PDF of parameters $\beta_{0}, \beta_{1}, \beta_{2}, \beta_{3}, \beta_{4}$ and $\mathrm{s}$ by the same form as Eq. (6). The data points used to evaluate Eq. (5) are presented in Figure 2 (a) and (b) (Ibisoglu, 2013). Table 6 summarizes the results of the estimated parameters.

\begin{tabular}{c|l}
\hline Parameter & Mean \\
\hline$\beta_{0}$ & 1.1670 \\
\hline$\beta_{1}$ & 4.8890 \\
\hline$\beta_{2}$ & -4.5960 \\
\hline$\beta_{3}$ & 0.9941 \\
\hline$\beta_{4}$ & -10.4500 \\
\hline $\mathrm{s}$ & 0.0537 \\
\hline
\end{tabular}

Table 6. WinBUGS statistics of the modified CF Soviet model parameters

\subsection{Bayesian Estimation of the Robust Fii Model}

Linearized Wilshire Model (Wilshire et al., 2009) and the normalized reference stress $(\Phi)$ model (Holmström \& Auerkari, 2013) using Eq. (3) and Table 1 are presented in Eq. (7) and Eq. (8). This form of the models was used in subsequent Bayesian Inference framework steps. $Q_{c}^{*}$ is the activation energy calculated for each of the $\mathrm{CF}$ tests in this study (Ibisoglu, 2013). The average of the $\mathrm{Q}_{\mathrm{c}}^{*}$ for the strain controlled CF tests was calculated to be $263,917 \mathrm{~J} / \mathrm{mol}$. After dividing this value using gas constant $\mathrm{R}$ (8.314 $\mathrm{J} / \mathrm{mol}^{\circ} \mathrm{K}$ ), the term $\frac{\mathrm{Q}_{\mathrm{C}}^{*}}{\mathrm{RT}}$ could be expressed as $\frac{31,744}{\mathrm{~T}}$.

$$
\begin{gathered}
\ln \left[-\ln \left(\sigma_{\text {ref }} / \sigma_{\mathrm{UTS}}\right)\right]=\operatorname{lnk}+\mathrm{u}\left[\ln \left\{\mathrm{t}_{\mathrm{CF}} \exp \left(-\mathrm{Q}_{\mathrm{c}}^{*} / \mathrm{RT}\right)\right\}\right] \\
\Phi_{\mathrm{CF}}\left(\Delta \varepsilon, \mathrm{t}_{\mathrm{h}}, \mathrm{T}\right)=\mathrm{c}_{1}+\frac{\mathrm{c}_{2}}{\Delta \varepsilon}+\mathrm{c}_{3} \log \left(\mathrm{t}_{\mathrm{h}}\right)+\mathrm{c}_{4} \mathrm{~T}
\end{gathered}
$$

Similarly, the likelihood function of the form given by Eq. (5) and the posterior joint PDF of parameters $\mathrm{k}, \mathrm{u}$, $c_{1}, c_{2}, c_{3}, c_{4}$ and $\mathrm{s}$ as described by the form given by Eq. (6) may be used. The data points used to evaluate Eq. (5) are presented in Figure 2 (a) and (b) (Ibisoglu, 2013). Table 7 and 8 summarizes the results of the estimated parameters.

\begin{tabular}{c|l}
\hline Parameter & Mean \\
\hline $\mathrm{k}$ & 4.9680 \\
\hline $\mathrm{u}$ & 0.0851 \\
\hline $\mathrm{s}$ & 0.0267 \\
\hline
\end{tabular}

Table 7. WinBUGS statistics for the Wilshire model parameters

\begin{tabular}{c|l}
\hline Parameter & Mean \\
\hline $\mathrm{c}_{1}$ & 2.7220 \\
\hline $\mathrm{c}_{2}$ & -0.0216 \\
\hline $\mathrm{c}_{3}$ & -0.0308 \\
\hline $\mathrm{c}_{4}$ & -0.0022 \\
\hline $\mathrm{s}$ & 0.0567 \\
\hline
\end{tabular}

Table 8. WinBUGS statistics of the normalized reference stress $(\boldsymbol{\Phi})$

\section{Comparison of the Proposed CF Life Models}

Figure 3 presents a comparison of CF life models for the 316 stainless steel. Predicted time-to-creep-rupture and time-to-CF-failure fall on the same material-specific master curves (Holmström \& Auerkari, 2013). In this figure, the stress is shown as a function of temperature-compensated life (i.e., $\mathrm{t}_{\mathrm{CF}}$ for $\mathrm{CF}$ ).

The goodness of fit can be expressed as the scatter factor $\mathrm{Z}$ (Larson \& Miller, 1952) given by Eq. (9):

$$
\mathrm{Z}=10^{2.5 \cdot \sqrt{\frac{\left(\left(\log \left(\mathrm{t}_{\mathrm{CF}}\right)-\log \left(\sum \mathrm{t}_{\mathrm{h}}\right)\right)\right)^{2}}{\mathrm{n}-1}}}
$$


where $\mathrm{n}$ is the number of data points. In this study, the agreement between predicted and observed CF life is for all of the model predictions $\mathrm{Z} \leq 4.93$. Assuming a normal distribution for CF life, the observed $\log \left(\mathrm{N}_{\mathrm{CF}}\right)$ was within the predicted $\log \left(\mathrm{N}_{\mathrm{CF}}\right) \mp \log (\mathrm{Z})$ for $99 \%$ of the observed cases. A comparison of the predicted vs. observed CF life in terms of time-to-failure is shown in Figure 4(a)-(e). Accordingly, Larson-Miller and Soviet Models (SM1 \& SM2) demonstrates better prediction features, regarding their smaller scatter factor $Z$.

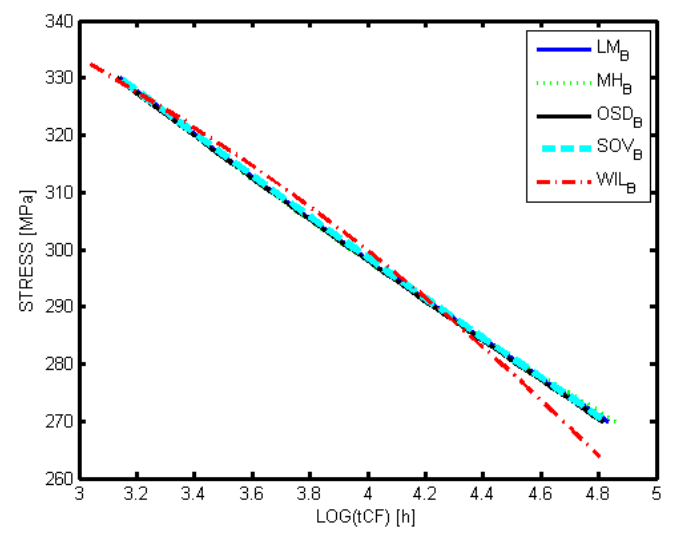

Figure 3. Time to $\mathrm{CF}$ failure Bayesian comparison master curve for the 316FR stainles steel for Larson-Miller (LM), Manson-Haferd (MH), Orr-Sherby Dorn (OSD), Soviet Model (SOV) (SM1 \& SM2), and Wilshire (WIL) Model

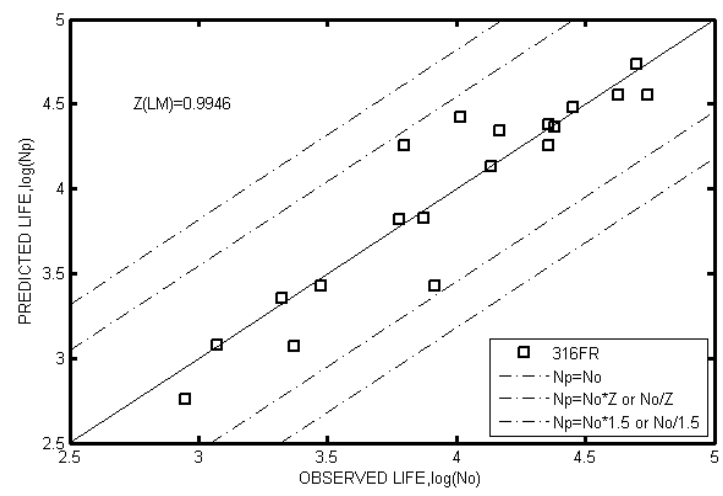

(a)

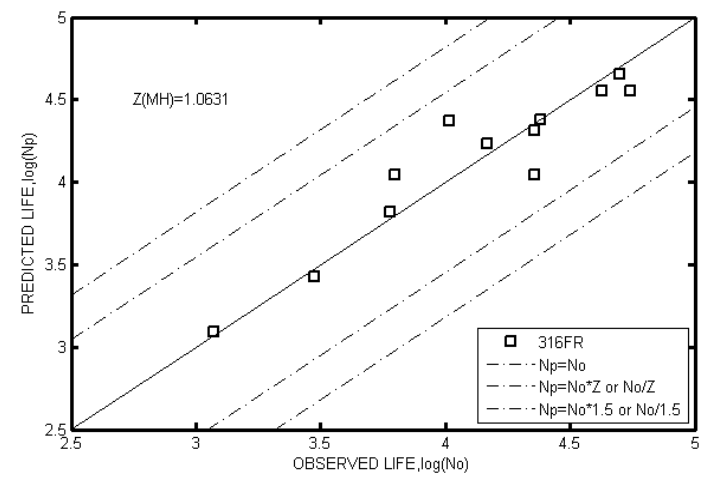

(b)

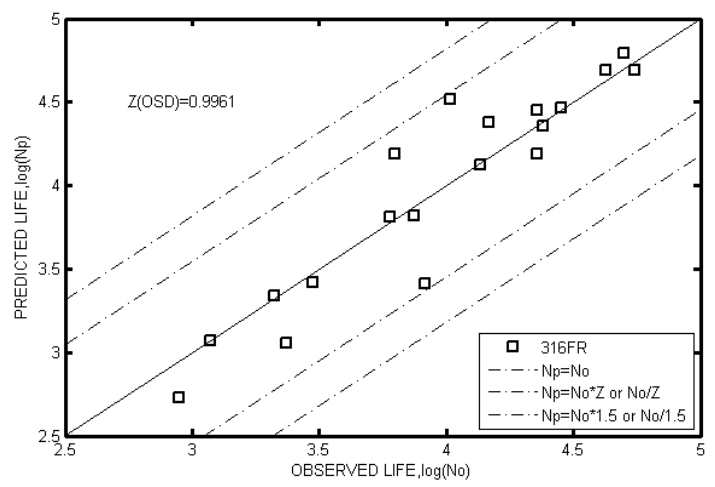

(c)

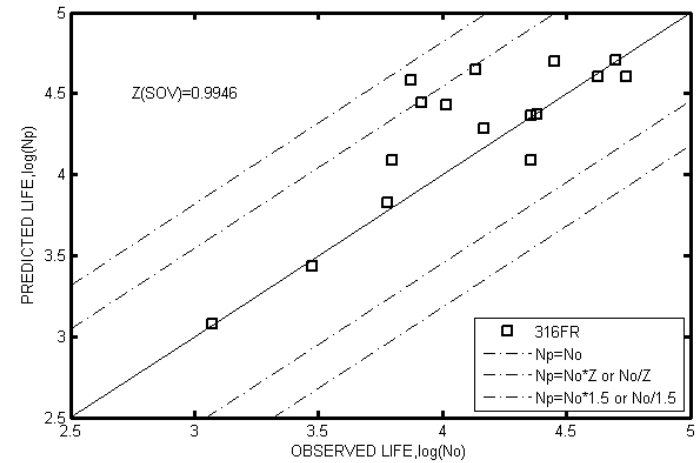

(d)

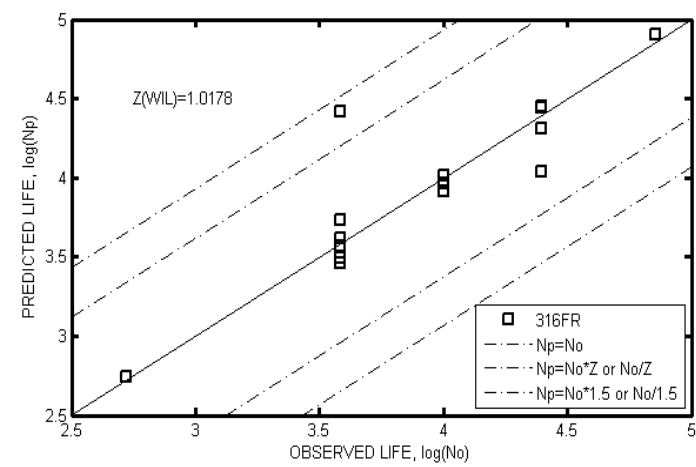

(e)

Figure 4. A comparison of the Bayesian predicted vs. observed CF life in terms of time to failure for (a) LarsonMiller, (b) Manson-Haferd, (c) Orr-Sherby Dorn, (d) Soviet Model (SM1 \& SM2), and (e) Wilshire Model

\section{Conclusions}

If the predictive capability of creep-fatigue life at high temperature can be improved, then statically, a more efficient design should be feasible. This study proposed modifications to some of the existing creep models to arrive at new CF life assessment models. These models were used to estimate the CF expended life. Experimental results for the $316 \mathrm{FR}$ stainless steel, which is of current interest as structural material for Generation IV nuclear power plants, were used to estimate the parameters of the proposed models using the Bayesian regression approach. The 
Bayesian statistical treatment of CF life produced results that agree well with nitrogen-controlled 316 stainless steel test data from Takahashi et al. (2008b). Comparisons of the life predictions from these models to the experimental results were within a scatter factor, Z, of close to one, which is of substantial improvement comparing to the result discussed in Holmström and Auerkari (2013), which reported a scatter factor of $\mathrm{Z}_{316 \mathrm{FR}}=2.50$. Assuming normal distribution for CF life, the observed $\log \left(\mathrm{N}_{\mathrm{CF}}\right)$ lies in almost $99 \%$ of the observed times within predicted $\log \left(\mathrm{N}_{\mathrm{CF}}\right) \mp$ $\log (Z)$.

Four existing creep-rupture models were modified and along with the Wilshire model used explain simultaneous CF loading and estimate the expended life of the structures with no need to separately treat the creep and fatigue mechanisms. Isothermal CF tests under strain control, with stress ratio $\mathrm{R}=-1$ and hold periods in tension that were conducted on stainless steel alloy test samples were used to produce experimental results to compare the modified CF life models. Of the modified models, Larson Miller and Soviet Models (SM1 \& SM2) behaved better to predict CF life in advanced nuclear reactor structural materials, where strain rates and cyclic frequencies are low and dominated by creep.

\section{NOMENCLATURE}

$\begin{array}{ll}\text { CDM } & \text { Continuum Damage Mechanics } \\ \text { CF } & \text { Creep-Fatigue } \\ \text { LCF } & \text { Low Cycle Fatigue } \\ \text { LDS } & \text { Linear Damage Summation } \\ \text { PDF } & \text { Probability Distribution Function } \\ \text { SEP } & \text { Strain Energy Partitioning } \\ \mathrm{SM} & \text { Soviet Model } \\ \mathrm{SRP} & \text { Strain Range Partitioning } \\ \Delta & \text { displacement } \\ \varepsilon & \text { strain } \\ \Delta \varepsilon & \text { strain range } \\ \Phi & \text { normalized reference stress } \\ \mathrm{N}_{\mathrm{fo}} & \text { cycles to end criterion without hold } \\ \mathrm{N}_{\mathrm{CF}} & \text { number of cycles-to-failure } \\ \mathrm{Q}_{\mathrm{c}}^{*} & \text { activation energy } \\ \sigma_{\mathrm{ref}} & \text { reference stress } \\ \mathrm{t} & \text { time } \\ \mathrm{t}_{\mathrm{h}} & \text { hold time } \\ \mathrm{T} & \text { temperature in }{ }^{\circ} \mathrm{K} \\ \mathrm{T}_{0} & \text { material specific temperature in }{ }^{\circ} \mathrm{K} \\ \mathrm{t}_{\mathrm{CF}} & \text { time-to-creep-fatigue failure } \\ \mathrm{t}_{\mathrm{r}} & \text { time-to-rupture from isothermal stress- } \\ \mathrm{t}_{\mathrm{h}} & \text { rupture curve } \\ \beta, \mathrm{c}, \mathrm{k}, \mathrm{u}, \mathrm{q}, \mathrm{r}, \log \mathrm{t}_{0} & \text { hold time } \\ \end{array}$

\section{REFERENCES}

Anon. Code Case N-47 (1976). ASME boiler and pressure vessel code, Criteria for design of elevated temperature,
Class I Components in section III, division 1, American Society of Mechanical Engineers.

Asayama, T., \& Tachibana, Y. (2007). Collection of Available Creep-Fatigue Data and Study Existing Creep Fatigue Evaluation Procedures for Grade 91 and Hastelloy XR. JAEA Task 5 Report, Sept 30. Retrieved from http://www.osti.gov/scitech/servlets/purl/974282

Asayama, T. (2009). Methodology for the Determination of a Set of Safety Factors That are Consistent for Design Code and Fitness-for-Service Code: Case Study for Fast Breeder Reactors. ASME 2009 Pressure Vessels and Piping Conference (pp.705-710), 26-30 July, Prague, Czech Republic. doi:10.1115/PVP2009-77686

Brinkman, C.R. (1985). High-Temperature Time-Dependent Fatigue Behavior of Several Engineering Structural Alloys. International Metals Review, Vol.30, No.5, pp.235-258. doi:10.1179/imr.1985.30.1.235

Chen, L.J., Wang, Z.G., Yao, G. \& Tian, J.F. (2008). An Assessment of Three Creep-Fatigue Prediction Methods for Nickel-Based Superalloy GH4049. Fatigue Fract Engng Mater Struct, Vol.23, pp.509-519. doi:10.1046/j.1460-2695.2000.00311.x

Evans. M. (1999). Method for Improving Parametric Creep Rupture Life of 2.25Cr-1Mo Steel using Artificial Neural Networks. Materials Science and Technology, Vol.15, Issue:6, pp.647-658. doi:10.1179/026708399101506391

Fan, Z., Chen, X., Chen, L. \& Jiang, J. (2007). FatigueCreep Behavior of $1.25 \mathrm{Cr} 0.5 \mathrm{Mo}$ Steel at High Temperature and Its Life Prediction. International Journal of Fatigue, Vol.29, pp.1174-1183. doi:10.1016/j.ijfatigue.2006.07.008

Fatemi, A., \& Yang, L. (1998). Cumulative Fatigue Damage and Life Prediction Theories: A Survey of the State of the Art for Homogenous Materials. International Journal of Fatigue, Vol.20, Issue:1, pp.9-34. doi:10.1016/S0142-1123(97)00081-9

Forman, R.G. (1972). Study of Fatigue Crack Initiation from Flaws using Fracture Mechanics Theory. Engineering Fracture Mechanics, Vol.4, Issue:2, pp.333-345. doi:10.1016/0013-7944(72)90048-3

Goswami, T. (2004). Development of Generic CreepFatigue Life Prediction Models. Materials and Design, Vol.25, pp.277-288. doi:10.1016/j.matdes.2003.11.001

He, J.R., Duan, Z.X., Ning, Y.L. \& Zhao, D. (1985). Strain Energy Partitioning and Its Application to GH33 A NiBase Superalloy and 1Cr18Ni9Ti Stainless steel. Acta Metalurgica. Sinica, Vol:21 A., pp.54-62 (in Chinese). Retrieved from http://www.ams.org.cn/EN/volumn/volumn_1399.shtml

Holmström, S. \& Auerkari, P. (2013). A Robust Model for Creep-Fatigue Life Assessment. Materials Science and Engineering A, Vol.559, pp.333-335. doi:10.1016/j.msea.2012.08.107

Holmström, S., Pohja, R., Nurmela, A., Moilanen, P., \& Auerkari, P. (2013). Creep and Creep-Fatigue Behavior 
of 316 Stainless Steel. 6th International Conference on Creep, Fatigue and Creep-Fatigue Interaction [CF-6], Procedia Engineering, Vol.55, pp.160-164. doi:10.1016/j.proeng.2013.03.236

Ibisoglu. F. (2013). Probabilistic Models for Creep-Fatigue in a Steel Alloy, Master's thesis, University of Maryland, College Park. ProQuest/UMI. (Publication No. AAT 1541465.). Retrieved from http://drum.lib.umd.edu/bitstream/1903/14296/1/Ibisogl u_umd_0117N_14255.pdf

Jeong, C.Y., Choi, B.G. \& Nam, S.W. (2001). Normalized Life Prediction in Terms of Stress Relaxation Behavior under Creep-Fatigue Interaction. Materials Letters, Vol.49, Issue.1, pp.20-24. doi:10.1016/s0167577X(00)00334-7

JianPing, J., Guang, M., Yi, S. \& SongBo, X. (2003). An Effective Continuum Damage Mechanics Model for Creep-Fatigue Life Assessment of a Steam Turbine Rotor. International Journal of Pressure Vessels and Piping, Vol.80, pp.389-396. doi:10.1016/S03080161(03)00070-X

Larson, F.R., \& Miller, J. (1952). A Time-Temperature Relationship for Rupture and Creep Stresses. Trans. ASME 74, pp.765-775.

Lloyd, G.J. \& Wareing, J. (1981). Life-Prediction Methods for Combined Creep-Fatigue Endurance. Metals Technology, Vol.8, Issue:1, pp.297-305. doi:http:10.1179/030716981803275262

Modarres, M., Kaminskiy, M., \& Kristov, V. (2010). Reliability Engineering and Risk Analysis, A Practical Guide, 2nd Edition, FL:CRC Press.

Nam, S.W. (2002). Assessment of Damage and Life Prediction of Austenitic Stainless Steel under High Temperature Creep-Fatigue Interaction Condition. Materials Science and Engineering:A, Vol.322, Issues:1-2, pp.64-72. doi:10.1016/S09215093(01)01118-2

National Aeronautics and Space Administration. (1953). A Linear Time-Temperature Relation for Extrapolation of Creep and Stress-Rupture Data. TN-2890, Technical Report. Manson, S.S., Haferd, A.M.

National Aeronautics and Space Administration. (1963). Design Considerations for Long Life at Elevated Temperatures. TP 1-63. Manson, S.S.

National Aeronautics and Space Administration. (1965). Optimization of Time-Temperature Parameters for Creep and Stress Rupture, with Application to Data from German Cooperative Long-Time Creep Program. TN D-2975. Mendelson, A., Roberts, E., Manson. S.S. Retrieved from

http://oai.dtic.mil/oai/oai?verb=getRecord\&metadataPr efix $=$ html\&identifier $=$ ADA396841

National Aeronautics and Space Administration. (1971). Ductility Normalized Strain Range Partitioning Life Relations for Creep-Fatigue Life Predictions. TMX 67838. Halford, G.R., Saltsman, J.F. and Hirschberg, M.H.
Nicholas, T. (1990). Fatigue Crack Growth Modeling at Elevated Temperatures Using Fracture Mechanics in Elevated Temperature Crack Growth, MD-Vol. 18, Mall, S. and Nicholas, T., Eds., American Society of Mechanical Engineers, New York, pp.107-112.

Orr, R.L., Sherby, O.D., \& Dorn, J.E. (1954). Correlation of Rupture Data for Metals at Elevated Temperatures. Trans. ASM 46, 113. Retrieved from http://oai.dtic.mil/oai/oai?verb=getRecord\&metadataPr efix $=$ html\&identifier $=$ AD0016713

Parida, B.K., \& Nicholas, T. (1992). Frequency and Hold Time Effects on Crack Growth of Ti-24Al-11Nb at High Temperature. Materials Science and Engineering $A$, Vol.153, Issue:1-2, pp.493-498. doi:10.1016/09215093(92)90242-S

Pavese, F., Bar, M., Filtz, J-R., Forbes, A.B., Pendrill, L., \& Shirono, K. (Eds.) (2012). Advanced Mathematical and Computational Tools in Metrology and Testing IX, Series on Advances in Mathematics for Applied Sciences - Vol.84, pp.377-384.

Riou, B. (2008). Improvement of ASME Section III-NH for Grade 91 Negligible Creep and Creep Fatigue. ASME ST LLC, DOE/ID14712-3.

Saxena, A. (1980). Creep Crack Growth under Non-Steady State Conditions, Fracture Mechanics in 17th Conference STP 905, ASTM Special Technical Publication, pp.247-255.

Scholz, A. \& Berger, C. (2005). Deformation and Life Assessment of High Temperature Materials under Creep Fatigue Loading. Materialwissenschaft und Werkstofftechnik, Vol.36, Issue:11, pp.722-730. doi:10.1002/mawe.200500941

Shang, D., Sun, G., Yan, C., Chen, J. \& Cai, N. (2007). Creep-Fatigue Prediction under Fully-Reversed Multiaxial Loading at High Temperatures. International Journal of Fatigue, Vol.29, Issue:4, pp.705-712. doi:10.1016/j.ijfatigue.2006.06.010

Takahashi, Y., Shibamoto, H., \& Inoue, K. (2008a). LongTerm Creep Rupture Behavior of Smoothed and Notched Bar Specimens of Low-Carbon NitrogenControlled 316 Stainless Steel (316FR) and Their Evaluation. Nuclear Engineering and Design, Vol.238, Issue:2, pp.310-321. doi:10.1016/j.nucengdes.2006.09.010

Takahashi, Y., Shibamoto, H. \& Inoue, K. (2008b). Study on Creep-Fatigue Life Prediction Methods for LowCarbon Nitrogen-Controlled 316 Stainless Steel (316FR). Nuclear Engineering and Design, Vol.238, Issue:2, pp.322-335. doi:10.1016/j.nucengdes.2006.09.017

Trunin, I.I., Golobova, N.G. \& Loginov, E.A. (1971). New Method of Extrapolation of Creep Test and Long Time Strength Results. In Proceedings of the Fourth International Symposium on Heat-Resistant Metallic Materials, Mala Fatra, CSSR, pp.168-176.

Wendell, F. (2011). A Handbook on Accelerated Testing. In fulfillment of the Scholarly Paper Requirement for the 
Degree of Master of Science in Reliability Engineering, Modarres, M. (Adv.), Department of Mechanical Engineering, University of Maryland, College Park.

Wilshire, B., Scharning, P., \& Hurst, R. (2009). A New Approach to Creep Data Assessment. Material Science and Engineering:A, Vol.510-511, pp.3-6. doi:10.1016/j.msea.2008.04.125

Zhao, J., Li, D-M., \& Fang, Y-Y. (2010). Application of Manson-Haferd and Larson-Miller Methods in Creep Rupture Property Evaluation of Heat-Resistant Steels. J. Pressure Vessel Technol., Vol.132, Issue:6, pp.064502-064502-4. doi:10.1115/1.4001916

Zhang, G., Yuan, H. \& Li, F. (2012). Analysis of CreepFatigue Life Prediction Models for Nickel-Based Super Alloys. Computational Materials Science, Vol.57, pp.80-88. doi:10.1016/j.commatsci.2011.07.034

\section{APPENDIX}

\begin{tabular}{lll}
\hline Temperature & $\begin{array}{l}\text { 0.2\% proof } \\
\text { stress } \\
\text { (MPa) }\end{array}$ & $\begin{array}{l}\text { Tensile } \\
\text { strength } \\
\text { (MPa) }\end{array}$ \\
\hline Room temperature & 255 & 568 \\
$550^{\circ} \mathrm{C}$ & 127 & 402 \\
\hline
\end{tabular}

Tensile properties of test material from Takahashi et al. (2008a)

\begin{tabular}{lll}
\hline $\begin{array}{l}\text { Temperature } \\
\left({ }^{\circ} \mathrm{C}\right)\end{array}$ & Stress (MPa) & $\begin{array}{l}\text { Rupture time } \\
\text { (h) }\end{array}$ \\
\hline 550 & 353 & 218 \\
550 & 323 & 857 \\
550 & 304 & 4,519 \\
550 & 304 & 8,759 \\
550 & 284 & 10,396 \\
550 & 284 & 14,112 \\
550 & 274 & 12,594 \\
550 & 265 & 33,966 \\
550 & 255 & 73,703 \\
550 & 245 & 94,177 \\
550 & 225 & $>82,287$ \\
600 & 265 & 242 \\
600 & 245 & 1,318 \\
600 & 225 & 5,851 \\
600 & 206 & 13,288 \\
600 & 196 & 17,435 \\
600 & 176 & 34,244 \\
\hline
\end{tabular}

\begin{tabular}{|c|c|c|c|}
\hline Temperature $^{\circ} \mathrm{C}$ & $\begin{array}{l}\text { Strain } \\
\text { range } \\
(\%)\end{array}$ & $\begin{array}{l}\text { Hold time } \\
\text { (h) }\end{array}$ & $\begin{array}{l}\text { Number } \\
\text { of cycles } \\
\text { to failure }\end{array}$ \\
\hline \multirow[t]{19}{*}{550} & \multirow[t]{6}{*}{1} & 0 & 2,736 \\
\hline & & 0.167 & - \\
\hline & & 1 & 973 \\
\hline & & 3 & 786 \\
\hline & & 10 & 453 \\
\hline & & 50 & 343 \\
\hline & \multirow[t]{5}{*}{0.5} & 0 & 17,190 \\
\hline & & 0.167 & 11,040 \\
\hline & & 1 & 6,150 \\
\hline & & 3 & 3,601 \\
\hline & & 10 & 2,147 \\
\hline & \multirow[t]{2}{*}{0.4} & 0 & 159,890 \\
\hline & & 0.167 & 54,623 \\
\hline & \multirow[t]{4}{*}{0.35} & 0 & $2,435,608$ \\
\hline & & 0.1 & 204,374 \\
\hline & & 1 & 35,094 \\
\hline & & 10 & $>3,790$ \\
\hline & \multirow[t]{2}{*}{0.3} & 0 & $9,200,000$ \\
\hline & & 1 & $>45,805$ \\
\hline \multirow[t]{10}{*}{600} & \multirow[t]{5}{*}{1} & 0 & 1,457 \\
\hline & & 0.167 & - \\
\hline & & 1 & 732 \\
\hline & & 3 & 622 \\
\hline & & 10 & 628 \\
\hline & \multirow[t]{3}{*}{0.5} & 0 & $2,549,493$ \\
\hline & & 1 & 5,187 \\
\hline & & 3 & 3,893 \\
\hline & \multirow[t]{2}{*}{0.35} & 0 & $1,043,233$ \\
\hline & & 1 & 22,556 \\
\hline
\end{tabular}

\section{BIOGRAPHIES}

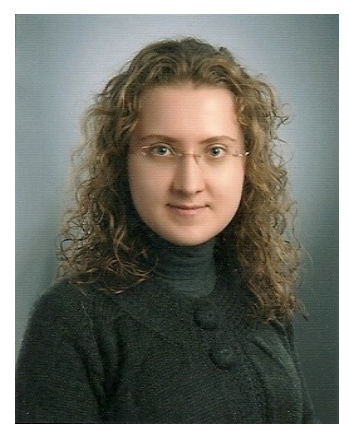

Fatmagul Ibisoglu is a mechanical engineering PhD student at Bogazici University. She earned her B.S. degree from Anadolu University in industrial engineering, a Master's degree from University of Maryland in reliability engineering. She was awarded with Fulbright Grant for her pursuit in Master's degree. She became a member of

Professor Mohammad Modarres' research group in 2011. Her research interests include microstructure evolution, probabilistic physics of failure, creep-fatigue, creep failure mechanism, genetic algorithms and design optimization. 


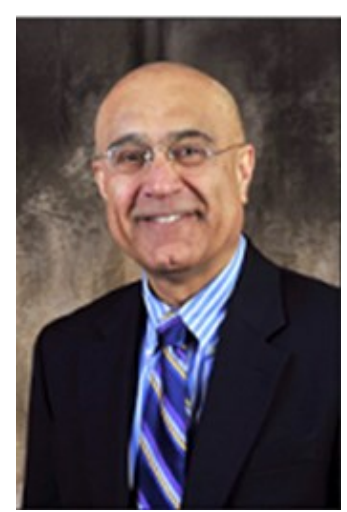

Mohammad Modarres is the Nicle Y. Kim Eminent Professor, and Director, Center for Risk and Reliability, University of Maryland, College Park. He specializes in probabilistic risk assessment and management, uncertainty analysis, probabilistic physics of failure and probabilistic fracture mechanics modeling. He earned his B.S. degree from Tehran Polytechnic in mechanical engineering, a Master's degree from Massachusetts Institute of Technology in mechanical engineering and a $\mathrm{PhD}$ from Massachusetts Institute of Technology in nuclear engineering. He has published over 300 papers in archival journals and proceedings of conferences. He has published a number of textbooks, edited books and book chapters in various areas of nuclear safety, risk and reliability engineering. He is a University of Maryland Distinguished Scholar-Teacher and a fellow of the American Nuclear Society. 